\title{
FATIGUE FRACTURES OF BOTH TIBIA AND FIBULA
}

\author{
Roy H. Maudsley, F.R.C.S. \\ Orthopadic Unit, Heatherwood Hospital, Ascot, Berks.
}

FATIGUE or stress fractures in the lower quarter of the fibula and of the tibia have been separately recorded, but only in one case have they been found in the same leg (Murray, 1957). The following two cases are therefore of some interest.

Case r.-E. G., a housewife and part-time domestic, aged 59, suddenly felt pain around the ankle while walking. Later the ankle became swollen but she remained active for six weeks until she attended her doctor, who referred her to Upton Hospital, Slough.

On examination, the lower leg and ankle were swollen, with maximal tenderness over the lower tibia and fibula. Ankle movements were restricted slightly and she walked with a limp. Radiographs were taken (see Fig. I).

A walking plaster was applied for a month and followed by a crepe bandage. Two months after her first attendance she had no pain or limp and only a little swelling at night. Four years later she had no symptoms and radiographs revealed no trace of fracture.

Case 2.-A. L., a housewife, aged 68, noticed the onset of pain over the outer side of the right ankle, also while walking. She regarded this as rheumatism but three weeks later attended her doctor, who referred her to hospital. Radiographs revealed transverse fractures about two inches above the malleoli (see Fig. 2).

A walking plaster was applied for six weeks. When the plaster was removed there was no pain, but a little swelling persisted in the ankle region together with a slight limp, and some increased valgus of the right foot was observed.

\section{Discussion}

Fatigue fractures of the tibia or fibula are not uncommon. Large series affecting the lower quarter of the fibula have been recorded by Burrows (1948), Devas and Sweetnam (1956) and others. In the lower tibia five cases were described by Singer and Maudsley (1954) and nine in athletes by Devas (1958).

These cases may be divided into $(a)$ the young and athletic and $(b)$ the middle-aged and tired. The majority appear in the former group, as does the only previously recorded case of fatigue fractures in both tibia and fibula (Murray, 1957). The two cases described in this article are in the 'middle-aged and tired' group. Neither of these patients attended until the symptoms had been present for six weeks and then they were not severe. It is possible that similar cases have occurred, but have not been radiographed nor recognized. From the radiographs of these two patients it will be seen that the callus in the $\vec{\omega}$ antero-posterior view is fairly even, though in thee lateral view it is wedge-shaped based posteriorly을 This would suggest the stress fracture com 3 menced posteriorly, during dorsiflexion.

From the numerous descriptions of fatigue fractures in many situations it is possible to describe severabs stages through which a fracture may pass (see Fig. 3).

Stage 1: The trabecular fracture in one cortex fol-o lowed by callus formation but no visible fracture line.? When the callus is adjacent to the periosteum, this is lifted up.

Stage 2: The fracture is continued through one cortex and an infraction is seen.

Stage 3: The fracture extends to the opposite cortex and a triangular zone of callus formed.

Stage 4: The fracture being complete, the fragmestsmay become displaced.

In the event these stages are determined whether the activity is continued after the first signs of fracture occur, by the amount of activity, and by the rate of healing in the fracture zone.

If these stages are truly progressive, it would seem to follow that the site of maximum callus is $\Rightarrow$ the site of first fracture. In the present cases and 3 on review of the literature of cases in the lower $\vec{T}$ third of the tibia the early callus appears posteriorly; this suggests that the bending strain is convex posteriorly and that the repetition action 3 . is dorsiflexion, or the forward thrust of the body weight through the knee.

Fatigue in metals is well understood and it $\delta$ may be well to consider the common and differing features. Any column of material when loaded 을 vertically is subject to compression stress. If the load is off centre, as in walking, deflection willo occur due to bending, with compressive and tensile $\stackrel{\sim}{N}$ strain on the inner or outer surfaces respectively. O If this column is subjected to repeated loading $N$ and relaxation there comes a time when the $\underset{\mathrm{E}}{\mathrm{N}}$ material reaches a point of fatigue. The number 0 of repetitive loadings to fatigue is very high in ${ }_{0}$ metals, but less in bones, and for the human tibia has been calculated by Evans (1957) to be about $\stackrel{?}{?}$ 2,000,000 in the centre of the shaft, but diminish- $T$ ing towards each end of the bone. The fibular 

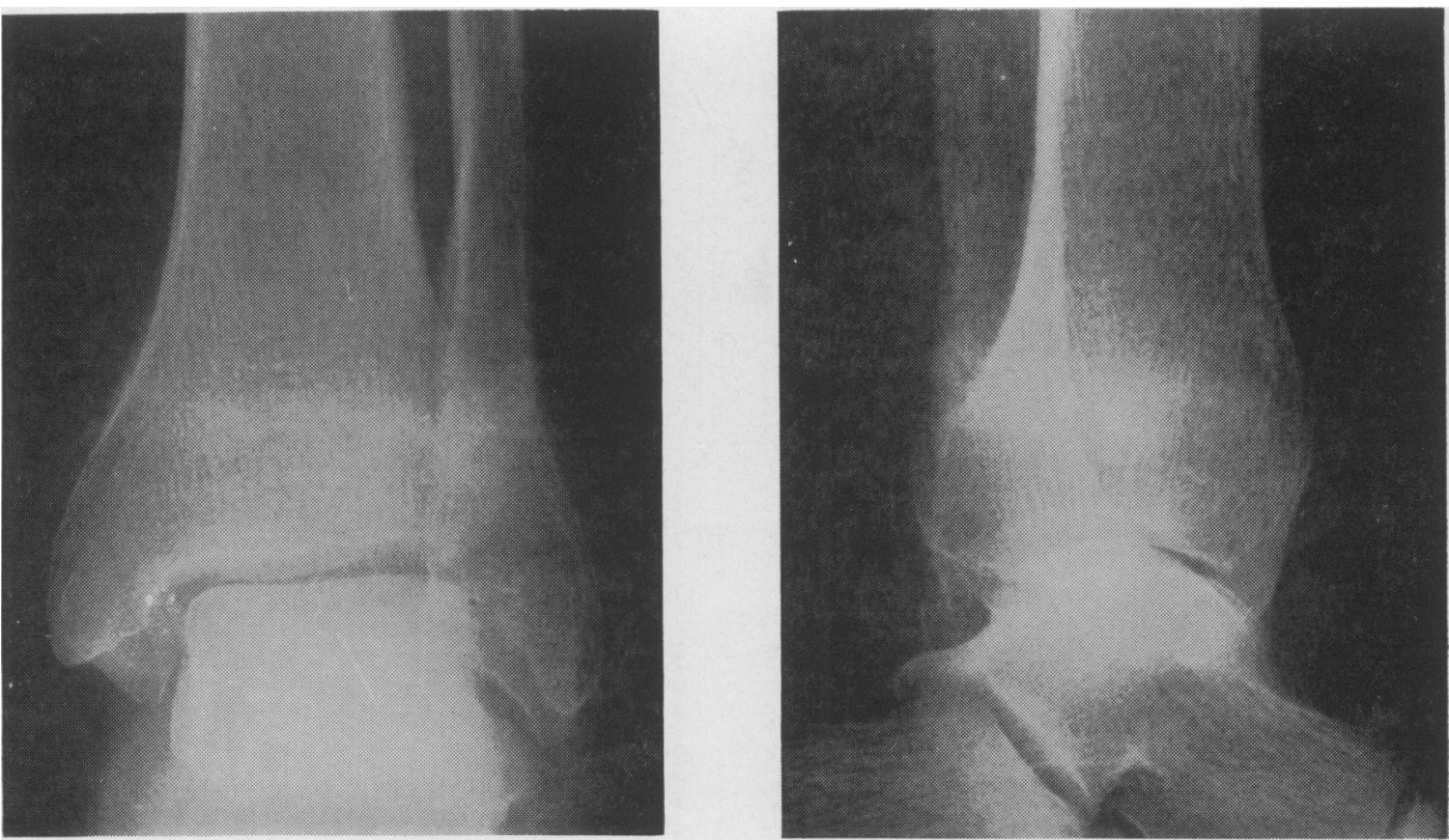

FIG. I.-Case I: Radiographs of transverse fatigue fracture of tibia and fibula with maximum callus posteriorly.
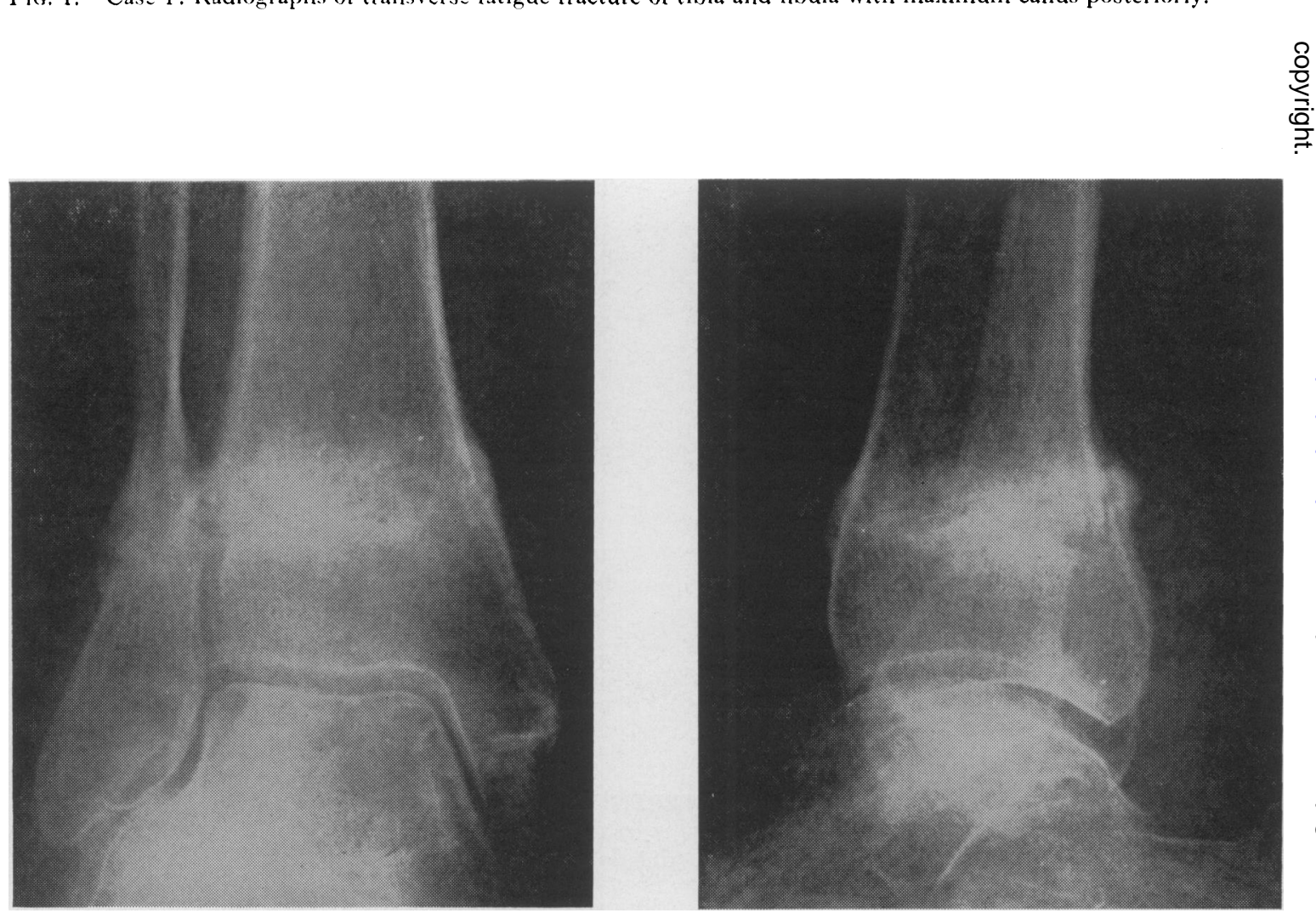

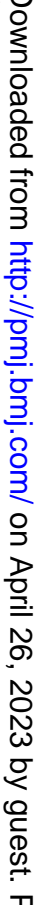

Fig. 2.-Case 2: Radiographs showing considerable callus formation transversely in the tibia and fibula, maximal posteriorly. 
FIg. 3.-Stages in fatigue fracture of a bone.

specimen had a life of $3,000,000$ cycles, all at $5,000 \mathrm{lb}$./sq. in. Evans has suggested that one reason for bone having a poorer fatigue life is its porosity (Haversian canals, etc.) compared with metals, and the increased porosity towards the ends of the shaft of a long bone might well account for a reduced fatigue life. Whereas a metal may be considered homogeneous, bone may not, since it has varying characteristics in stress at different levels and quadrants of the bone. Thus the stressstrain characteristics of the whole bone may not be assumed from the determinations on a unit portion of bone. Nevertheless, bone has a built-in organic capacity to repair that metal does not by virtue of osteoblastic action. Fatigue life is therefore likely to be reached only after excessive repeated loadings within the time required for repair, which may be prolonged in the case of the more elderly.

Individual trabeculæ may well be fractured at first and possibly lead to discomfort, which may determine rest and allow repair to occur. But if the activity be continued many trabeculæ will be fractured and lead to an infraction, though this may not occur until callus has commenced in response to the first minute fractures. In this way the well-known observation that callus is sometimes seen either without or before a fracture line can be explained. In a column such as bone there is bending in response to loading and this is known as elasticity. Devas and Sweetnam have suggested that the bending of the fibula toward the tibia by resisted muscular effort may be respon-G sible for fatigue fracture, but it would appearo normal for this to occur as part of the elasticity of the bone.

Burrows suggested that fatigue fractures occuro in the section of fibula where it changes from $\stackrel{\mathbb{D}}{\mathcal{3}}$ narrow compact bone to wide cancellous bone, and this has also been noted in the tibia (Singer ${ }^{-}$ and Maudsley, 1954). This level is a region increasing porosity and marks the end of the shaft where fatigue life becomes reduced (Evans, I95\%.

\section{Treatment}

Since callus is often well advanced when the patient is first seen, some restriction of activity $\mathbb{Q}$ with immobilization to give comfort for a few weeks is all that is required. Should an underlying윽 cause be suspected, a search for this should be undertaken, though in the vast majority of cases reported no positive findings have been made.

\section{Summary}

Two cases of fatigue fractures of the lower ends of both tibia and fibula of the middle-aged women are described, and the mechanism of fatigue fractures is discussed.

I am grateful to Mr. W. Herschell for permission to quote the second case, to Miss Beckett for the drawing of Fig. 3, and to Miss D. Bannister for the radiographic N prints.

\section{REFERENCES}

Burrows, H. J. (1948): Fatigue Fractures of the Fibula, $\mathcal{F}$. Bone $\mathcal{F} t$ Surg., 30B, 266.

Devas, M. B. (I958): Stress Fractures of the Tibia in Athletes or 'Shin Soreness', Ibid., 40 B, 227. , and SweEtnam, D. R. (1958): Runner's Fracture, Practitioner, 180, 340.

Evans, F. GAYNOR (1957): 'Stress and Strain in Bone'. Springfield, Illinois: Charles C Thomas.

Murray, D. S. (1957): Fatigue Fractures of the Lower Tibia and Fibula in the Same Leg, F. Bone Yt. Surg., 39B, 302. O

Singer, M., and Maudsley, R. H. (1954): Fatigue Fractures of the Lower Tibia, Ibid., 36B, 647. 